\title{
EFECTOS DE LAS SENTENCIAS CONSTITUCIONALES EN EL DERECHO ARGENTINO
}

\author{
EFFECTS OF CONSTITUTIONAL JUDGEMENT \\ IN ARGENTINIAN LAW
}

\section{Julia SÁNCHEZ SÁNCHEZ}

RESUMEN: La regulación de los efectos de las sentencias constitucionales en el derecho argentino, ha quedado a cargo, básicamente, del derecho consuetudinario procesal constitucional. Por un lado, la Corte Suprema de Justicia ha instrumentado además de las sentencias tradicionales, estimatorias o desestimatorias, sentencias de tipo "interpretativo", "manipulativo" (por adición, sustracción y sustitutivas), exhortativas y escalonadas. Por otro, partiendo del esquema inicial de fallos con efectos inter partes, la misma Corte ha creado la doctrina de la eficacia vinculante de la doctrina constitucional enunciada en sus sentencias, aunque permite apartarse de ella invocando el juez del caso razones valederas y diferentes a las ya evaluadas por la Corte. Por lo demás, los fallos declarativos de inconstitucionalidad tienen efecto retroactivo, pero existen significativas excepciones. En el derecho público provincial, a su turno, hay modalidades muy diversas de efectos erga omnes.

Palabras clave: Derecho consuetudinario procesal constitucional; sentencias: típica y atípica; interpretativa; manipulativa; exhortativa y escalonada, control difuso de constitucionalidad, efectos inter partes y erga omnes, mutaciones constitucionales, derecho público provincial.
ABSTRACT: The regulation of the effects of constitutional sentences in Argentinean Law has been in charge, basically, of the Consuetudinary Procedural Constitutional Law. In one hand, the Supreme Court of Justice has orchestrated, besides the traditional, estimative or negative sentences, other sentences newly coined; of "interpretative", "manipulative" (by addition, subs traction and substitutive), exhortative and staggered type. On the other hand, starting on the initial scheme of judgment with inter partes effects, the same Court has created the doctrine of the binding effectiveness of the constitutional doctrine formulated in its sentences, although it allows to move over from her invoking the judge of the case the valid reasons and the differences with those already evaluated by the Court. For else, the declaratives judgments of unconstitutionality have retroactive effect, but there are significant exceptions. In the provincial public Law, there are in turn, very diverse modalities of erga omnes effects.

Descriptors: Consuetudinary Procedural Constitutional Law. Sentence: traditional, untraditional, interpretative, manipulative, exhortative, stagger. Constitutional Diffuse Control. Inter partes and erga omnes effects. Constitutional mutations. Provincial public Law. 


\section{INTRODUCCIÓN}

Argentina es un Estado federal, muy apegado al esquema estadounidense. ${ }^{1}$ En materia de control de constitucionalidad, también ha seguido las pautas iniciales sentadas en este país. Sin embargo, y a pesar de la similitud de los dos textos constitucionales en esta temática, en la actualidad la fisonomía de la Corte Suprema nacional no es la misma en ambas naciones. Mientras que en Estados Unidos la Corte se ocupa de no más de cien sentencias anuales, que abordan temas principalmente constitucionales, la Corte Suprema argentina es un tribunal de "ramos generales" (como lo hemos llamado desde años atrás), que diligencia miles de casos de derecho constitucional pero también de derecho civil, comercial, penal, laboral o tributario, entre otros. En ciertos momentos pudo afirmarse que es la Corte Suprema con mayor cantidad de trabajo en el mundo.

Por lo demás: dado que cada provincia (o estado federado) argentina puede adoptar esquemas propios en materia de organización jurisdiccional, los efectos de las sentencias no son exactamente iguales en el ámbito nacional y en el provincial. Marcaremos al final de este trabajo (que se centra, particularmente, en la esfera nacional) algunas notas distintivas.

El presente artículo tiene por meta describir cuáles son las clases de sentencias constitucionales que maneja la Corte Suprema de Argentina, y reseñar los principales resultados que ellas tienen en la experiencia jurídica concreta.

1 En determinados puntos, el federalismo estadounidense es más intenso que el argentino. Por ejemplo, el "derecho común" (civil, comercial, penal) está regulado en los Estados Unidos por los estados, mientras que en Argentina existe una legislación uniforme en tales materias, dictada por el gobierno nacional. En verdad, según el modelo de Juan B. Alberdi, en gran medida autor intelectual de la Constitución argentina de 1853, ésta no programa una federación pura, sino un ente híbrido, mixto o compuesto, de una "federación unitaria", o una "unidad federativa". Véase Alberdi, Juan Bautista, "Bases y puntos de partida para la organización política de la República Argentina”, Organización política y económica de la Confederación Argentina (Besanzón, 1856), nueva edición oficial, cap. XXIV, p. 100. 


\section{SENTENCIAS TÍPICAS}

Liminarmente debe recordarse que el régimen argentino nacional de control judicial de constitucionalidad ${ }^{2}$ es difuso, desconcentrado o disperso (cualquier juez "judicial" puede reputar inconstitucional a una norma, y ello le implica un deber, de darse las condiciones del caso), ${ }^{3}$ fundamentalmente letrado (aunque puede haber jueces "legos", no titulados en derecho, también con competencia para resolver temas constitucionales), permanente, impulsable a requerimiento de parte (por vía de "excepción" o de "acción"), o por el propio juez ("de oficio"), y con un amplio margen de cobertura, ya que el territorio de las cuestiones políticas no justiciables (political questions) se ha reducido sensiblemente en los últimos lustros. Los efectos del veredicto debían ceñirse - teóricamente- al caso concreto (resultado inter partes), pero veremos más tarde que ello no es ahora exactamente así. ${ }^{4}$

No hay en Argentina un Tribunal Constitucional al estilo kelseniano, concentrado y especializado en temas constitucionales. La Corte Suprema de Justicia de la Nación, sin embargo, gusta definirse como un "tribunal de garantías" o de "derechos constitucionales", en el sentido que debe tutelarlos. ${ }^{5}$

En ese contexto, las sentencias "típicas" son las que declaran la inconstitucionalidad de un precepto (sentencias "admisorias" o "estimatorias", aunque esta terminología no es frecuente en Argentina), y las que rechazan el acuse de inconstitucionalidad ("desestimatorias").

2 Para la descripción del sistema argentino de control de constitucionalidad nos remitimos a Sagüés, Néstor Pedro, Derecho procesal constitucional. Recurso extraordinario, 4a. ed., Buenos Aires, Astrea, 2002, t. 1, pp. 98 y ss.

3 La habilitación del control de constitucionalidad es tanto para todos los jueces nacionales como provinciales. Véase Corte Suprema de Justicia de la Nación (en adelante, CSJN), Fallos, 312:2494.

4 Un problema particular suscitan los fallos "plenarios" o "plenos", de ciertos tribunales, por ejemplo de segunda instancia, que según el régimen legal en vigor sientan doctrina obligatoria para los jueces inferiores. Si la doctrina establecida es en materia constitucional, se estaría restringiendo la libertad de decisión de los jueces inferiores para declarar o no constitucional a una ley. En algún caso la Corte Suprema de Justicia ha dicho que los planteos de inconstitucionalidad no deben ser materia de los plenos o plenarios: CSJN, Fallos, 302:980.

5 Véase por ejemplo la sentencia pronunciada en Pérez de Smith, CSJN, Fallos, 297:338; o en el primer caso Timerman, Jurisprudencia Argentina, 1978-IV-121. 
En la experiencia judicial argentina se han presentado situaciones que son propias de un sistema difuso o desconcentrado de control de constitucionalidad. Por ejemplo, que un juzgado o un tribunal colegiado repute constitucional a una ley, y otro resuelva lo contrario. Si no median recursos idóneamente interpuestos contra esos fallos, pueden quedar firmes y ejecutoriados, circunstancia que posibilita que el sistema judicial dé respuestas contradictorias. Es cierto que una escalera procesal, el "recurso extraordinario federal" previsto en sus comienzos por el artículo 14 de la Ley 48, permite llevar todo expediente donde se decida la constitucionalidad o inconstitucionalidad de una norma presuntamente opuesta a la Constitución federal, ante la Corte Suprema Nacional, que consuma entonces una suerte de "casación federal". ${ }^{6}$ Sin embargo, este recurso, y los que pueden serle previos, no siempre son articulados en tiempo y forma.

Otra hipótesis llamativa es el caso de las "inconstitucionalidades evolutivas": una norma puede ser reputada en un fallo, por ejemplo de la Corte Suprema, como constitucional, pero en otro posterior del mismo tribunal, inconstitucional (veredicto que no la deroga), y en un tercer pronunciamiento de idéntica Corte, volver a ser juzgada como constitucional. ${ }^{7}$ Estos vaivenes son frecuentes cuando la integración de la Corte ha variado, alternativa que ocurre con cierta frecuencia. ${ }^{8}$ Algunas veces la Corte recurre al argumento de las inconstitucionalidades "sobrevinientes": una norma pudo haber sido constitucional al momento de sancionarse, pero después, por modificación del contexto de vida, o por variación en las creencias sociales, concluye como inconstitucional. ${ }^{9}$

Finalmente, un hecho igualmente curioso se da con las que hemos denominado "inconstitucionalidades relativas": un mismo precepto le-

6 Sobre el recurso extraordinario federal como mecanismo de casación federal, en orden a lograr una interpretación uniforme de la Constitución, derivamos al lector a nuestro Derecho procesal constitucional. Recurso extraordinario, op. cit., nota 2, t. 1 p. 299.

7 Respecto de las inconstitucionalidades evolutivas, puede mencionarse en Argentina en particular el caso Sejean, donde la Corte cambia el criterio sostenido hasta entonces de constitucionalidad de la prohibición de contraer nuevo matrimonio de haber divorcio vincular, por el de su inconstitucionalidad, al haber variado las creencias sociales sobre el tema. Véase infra, nota 45.

8 Los cambios en la Corte Suprema federal han sido frecuentes por la aparición de gobiernos de facto, y también con el posterior retorno a regímenes democráticos o de jure. Asimismo, ante variables de fuertes cambios políticos en los poderes Ejecutivo y Legislativo (casos de 1989 y 2003, por ejemplo).

9 Véase al respecto el caso Itzcovich, CSJN, La Ley, 2005-F-362. 
gal, por ejemplo, efectivizado sobre relaciones jurídicas similares, puede causar agravio constitucional a un litigante en determinado momento, pero no en otro. ${ }^{10}$ En tales supuestos, la norma en cuestión colisiona - o no- con la Constitución, según los periodos o situaciones a los que se la aplique.

\section{SENTENCIAS ATÍPICAS}

También la Corte Suprema argentina ha instrumentado sentencias constitucionales "atípicas", en el sentido que no siempre calzan dentro de la anterior categoría de fallos "admisorios" o "desestimatorios" de planteos de inconstitucionalidad de normas.

Mencionaremos algunas clases de estos veredictos.

a) Sentencias "interpretativas". Aplicando la doctrina de la interpretación de normas subconstitucionales "conforme" o "de acuerdo" con la Constitución, la Corte Suprema varias veces, y desde décadas atrás, ha condenado como inconstitucionales a las interpretaciones dadas a ciertos preceptos, pero no al precepto en sí mismo. La directriz es que, de admitir una regla jurídica una interpretación acorde con la Constitución, y otra opuesta a ella, debe preferirse a la primera. Ello implica proponer (y exigir) al operador jurídico, una interpretación "armonizante" o adaptadora entre la regla inferior (ley, decreto, resolución, etcétera) y la superior (la Constitución). ${ }^{11}$

10 Derivamos al lector a nuestra Interpretación judicial de la Constitución, 2a. ed., Buenos Aires, Lexis-Nexis, 2006, p. 201.

11 Sobre el tema de las interpretaciones inconstitucionales de normas subconstitucionales en la jurisprudencia de la Corte Suprema de Justicia de Argentina, véase Sagüés, Néstor Pedro, op. cit., nota 2, t. 2, p. 54. En tal sentido, cabe recordar como antecedentes los fallos de la Corte Suprema de Justicia de Argentina en Giacumelli c. Provincia de Santa Fe, CSJN, Fallos, 186:353, cuando alertó que una ley puede ser declarada inconstitucional no tan sólo por lo que es en sí, sino por la interpretación con que ha sido aplicada; la sentencia Meier, del 17/12/42 (Libro de sentencias, t., 63 p. 347), donde habla de la "la inconstitucionalidad de la interpretación de leyes comunes o locales"; y los veredictos vertidos en CSJN, Fallos, 102:379, 123:313, 124:395, citados en Giacumelli, CSJN, Fallos, 186:353. En el primero de éstos, repetido en los demás, la Corte advierte que le corresponde "únicamente decidir si tal interpretación (de la ley), se halla o no en conflicto con las disposiciones constitucionales...". Véase sobre el tema a quienes seguimos como fuente, Imaz, Esteban y Rey, Ricardo E., El recurso extraordinario, 2a. ed., Buenos Aires, Nerva, 1962, pp. 168 y ss., con formulaciones críticas sobre este tipo de 
Cabe alertar, eso sí, que la Corte Suprema argentina no usa la distinción operante en otras latitudes (España, v. $g r$.), entre "enunciado" o "disposición" jurídica, y las "normas" posibles de ser incluidas entre los enunciados o disposiciones, si es que éstos brindan diferentes alternativas de interpretación. ${ }^{12}$ Prefiere hablar de "interpretaciones" - constitucionales o no, según los casos-, de un precepto subconstitucional.

En definitiva, mediante el artilugio de la sentencia "interpretativa", la Corte Suprema califica como constitucional a cierta exégesis concreta de un precepto o disposición, descartando respecto de ella la objeción de ser inconstitucional, lo que deja abierta la posibilidad, mediante el argumento a contrario sensu, de reputar inconstitucional otra inteligencia distinta a la aceptada. ${ }^{13}$

Ahora bien: ¿cuál es el límite de la sentencia "interpretativa"? En su versión de sentencia adecuadora o adaptativa, ¿hasta cuánto puede encontrar variables interpretativas dentro de una "disposición"? Al respecto, podrá decirse que el operador dispone de un amplio margen de maniobra para interpretar, pero no para inventar variables interpretativas que no existan. La Corte Suprema de Justicia de Argentina, no sin acierto, ha puntualizado que la tarea de armonización de la norma inferior con la Constitución debe practicarse sin violentar la letra o el espíritu de la norma subconstitucional interpretada. ${ }^{14} \mathrm{El}$ operador del caso, no por hacer coincidir un precepto-disposición con la Constitución, está autoriza-

sentencias. Por el contrario, aprobando la doctrina de las sentencias que destruyen interpretaciones inconstitucionales de normas, pero no a éstas, Strohm Erick, "Sentencias inconstitucionales", Jurisprudencia Argentina, 1954-III-12, sec. Doctrina.

12 Véase Sánchez y Sánchez, Abraham, Sentencias interpretativas y control de constitucionalidad en Colombia, Bogotá, Ed. Gustavo Ibáñez, 2005, p. 162. Años atrás habíamos anticipado que una cláusula normativa que admitiese varias interpretaciones, por ejemplo tres, no era en rigor de verdad "una" norma, sino "tres", y que el operador judicial debía optar por una de ellas, desechando a las demás. Cfr. nuestro estudio La interpretación judicial de la constitución, cit., nota 10, p. 26.

13 Así, la Corte Suprema de Justicia de Argentina, en Oroz y Baretta (Fallos, 312:483), declaró constitucional al artículo 87 del Código de Procedimiento Penal de la Provincia de Buenos Aires, siempre que se entendiere que la limitación de las facultades del particular damnificado para interponer recursos extraordinarios locales que contiene, sea obviada cuando estén involucradas en los mismos cuestiones federales.

14 Por ejemplo, Corte Suprema de Justicia de Argentina, caso Outón, Fallos, 308:647. Nos hemos referido más extensamente al tema en nuestro Derecho procesal constitucional, cit., nota 2, t. 2, pp. 42 y ss. 
do para retorcerlo, desfigurarlo o estrujarlo para hacer salir de él una receta interpretativa que decididamente no tenga. Por ello, si aquel precepto no cobija una interpretación posible del mismo acorde con la Constitución, no habrá otro remedio que reputarlo inconstitucional.

b) Sentencias manipulativas. En la sentencia "manipulativa" (bien aclarado que este término no conlleva aquí sentido negativo o peyorativo), el operador judicial no encuentra una solución ya prexistente en las normas que hace funcionar, sino que elabora una respuesta nueva, agregándole, quitándole o sustituyendo algo al precepto en juego, fundamentalmente para hacer cumplir a la Constitución o para conciliarlo con ella.

(i) Un caso de sentencia manipulativa aditiva o sumatoria con enormes proyecciones económicas ha sido la dictada en el caso Massa, concerniente al tema de la "pesificación" dispuesta por una maraña de leyes, decretos de necesidad y urgencia y decretos reglamentarios, respecto de depósitos bancarios originalmente pactados en dólares. La Corte Suprema entendió que ese "bloque normativo de emergencia" no violaba al derecho de propiedad reconocido por la Constitución, pero siempre que asegurase la conversión de un peso con cuarenta centavos por cada dólar, con más una cifra proveniente del CER ("coeficiente de estabilización de referencia"), y un interés anual del 4\%, no capitalizable. De hecho, ello importó un agregado establecido judicialmente, a fin de evitar la declaración de inconstitucionalidad del referido "bloque normativo". ${ }^{15}$

(ii) A la inversa, un supuesto de sentencia manipulativa sustractiva fue la emitida por la Corte Suprema de Justicia en Ekmekdjian vs. Sofovich, con relación al ejercicio del derecho de rectificación o respuesta ("réplica"). Al respecto, el Pacto de San José de Costa Rica determina en su artículo 14 que tal derecho se ejerce "en las condiciones que establezca la ley”. Sin embargo, la Corte entendió que la inexistencia de ley no impedía que se practicara la réplica, por ejemplo a través de una sentencia judicial. ${ }^{16}$ En definitiva, la Corte eliminó un requisito previsto por el Pacto.

15 Cfr. Nuestro estudio "La decisión de la Corte Suprema argentina sobre pesificación de depósitos bancarios en dólares, desde la perspectiva procesal constitucional", $E l$ Derecho, Buenos Aires, 15-3-2007, p. 1.

16 Cfr. CSJN, La Ley, 1992-C-543. La Corte Suprema argentina, en verdad, siguió en esta operación sustractiva el criterio anterior expuesto por la Corte Interamericana de Derechos Humanos, en una opinión consultiva. Otra interpretación mutativa por sustracción fue realizada por la Corte Suprema, con relación a la acción de amparo, al obviar 
(iii) El caso Vizzotti es una muestra de sentencia manipulativa mixta, por sustracción-adición, vale decir, sustitutiva. En la misma se debatía la constitucionalidad de un tope o límite establecido por ley, respecto de las indemnizaciones por despido. La Corte entendió inconstitucional ese límite, y estableció discrecionalmente cuál debía ser la base correcta que cabía aplicar para graduar la reparación: la mejor remuneración mensual normal y habitual del último año, o del tiempo de prestación de servicios si éste fuera menor, con una reducción que no podría superar el 30\%. ${ }^{17}$

c) Sentencias exhortativas. También llamadas "apelativas", "con aviso" o "de encargo", asumen distintas modalidades. En términos generales, en ellas el órgano de la jurisdicción constitucional encomienda al legislador el dictado de una nueva norma en remplazo de la actual, reputada inconstitucional o de dudosa constitucionalidad. No frecuentes en el derecho argentino, emergen sin embargo en los últimos años.

Tal vez el caso más notorio ha sido Verbitsky, referido a un habeas corpus colectivo de tipo "correctivo", donde se procuró solucionar el problema del hacinamiento y pésima atención a personas privadas de su libertad en comisarías y cárceles de la Provincia de Buenos Aires. Al resolver la acción, la Corte advirtió que las leyes procesales penales de esa provincia en materia de detención provisoria, de excarcelaciones y de trato a los presos, no parecían ser constitucionales, en el sentido que colisionaban con reglas de la Constitución federal y con normas de tratados internacionales, algunos de ellos con rango constitucional a tenor del artículo 75 incico 22 de la referida Constitución. En resumen, "exhortó" a las autoridades de la referida provincia a dictar nuevas leyes de conformidad con las normas superiores mencionadas. Ello se hizo sin declarar inconstitucionales a las normas provinciales sospechadas de inconstitucionalidad, que padecerían, por lo visto, de lo que hemos denominado una suerte de "constitucionalidad endeble" o "precaria". ${ }^{18}$

para ejercitar tal acción el requisito exigido por el artículo 43 de la Constitución Nacional, respecto de las asociaciones, de estar registradas conforme a una ley que debía determinar los requisitos y formas de su organización: véase por ejemplo CSJN, "Asociación de Grandes Usuarios”, La Ley, 1997-C-322. En ese supuesto, lo reducido o sustraído fue una regla de la Constitución.

17 CSJN, en Jurisprudencia Argentina, 2004-IV-199.

18 CSJN, Fallos, 328:1146. La Corte Suprema advirtió que uno de cada cuatro detenidos era preso sin condena, y que cohabitaban menores con mayores, enfermos con sanos, muchas veces en simples comisarías y en condiciones infrahumanas. 
Más rotundo, el fallo pronunciado en Rosza declaró la inconstitucionalidad de la resolución 76/04 del Consejo de la Magistratura de la Nación, que dispuso un sistema de nombramiento de jueces federales suplentes o subrogantes que, al entender de la Corte Suprema, violaba la Constitución. Sin embargo, el tribunal, contemplando las graves y caóticas consecuencias que derivarían de aplicar drásticamente esa declaración de inconstitucionalidad, estableció también que los actos realizados por los jueces así nombrados serían válidos, y que ellos continuarían en sus cargos hasta que cesaran las razones por las cuales fueron nombrados, o en todo caso por un plazo máximo de un año más, término en el que el Congreso de la Nación y el Poder Ejecutivo debían sancionar un sistema de designación de dichos magistrados, compatible con la Constitución, según los lineamientos explicitados por la Corte. ${ }^{19}$ Esta sentencia exhortativa se enmarca por un lado dentro de las denominadas de "declaración simple de inconstitucionalidad", puesto que no nulificó a los nombramientos de los jueces designados inconstitucionalmente, ni a sus actos; y por otro, "exhortativa de delegación", porque estableció un plazo y fijó pautas de contenido a las cuales debían someterse los poderes Ejecutivo y Legislativo para elaborar la nueva norma. ${ }^{20}$

d) Sentencias escalonadas. Otra modalidad que ha ensayado recientemente la Corte Suprema ha sido programar, cuando resuelve ciertos casos trascendentes, un binomio de fallos. En el primero, sienta ciertas directrices a las que debe someterse el condenado. Se prevé también un segundo veredicto, donde evaluará el cumplimiento de la directriz determinada en el primer pronunciamiento.

Así, en Badaro, la Corte entendió que el sistema de ajuste de haberes jubilatorios dispuesto por el Estado no respetaba el principio de movilidad contemplado por el artículo 14 bis de la Constitución Nacional. Pero

19 CSJN, caso Rosza, sentencia del 23/5/2007, "Jurisprudencia Argentina" 2007-III-414. Al momento de dictarse el fallo por la Corte Suprema, aproximadamente el $25 \%$ de los jueces federales en ejercicio padecía del vicio de designación al que alude la Corte.

20 Sobre estas modalidades de sentencias exhortativas, nos remitimos a Sagüés, Néstor Pedro, Derecho procesal constitucional. Logros y obstáculos, Buenos Aires, Ad Hoc, 2006, pp. 77 y ss. Otra sentencia exhortativa de la Corte Suprema fue la segunda dictada en el caso Badaro (26/11/07), donde vuelve a encomendar al Congreso la sanción de una ley general que contemple adecuadamente la movilidad de las jubilaciones prevista por el artículo 14 bis de la Constitución Nacional. 
en lugar de determinar ella misma a cuánto debía ascender la actualización monetaria del caso, para el caso singular discutido en ese expediente, encomendó a los poderes Ejecutivo y Legislativo, a quienes corresponde en principio dictar las normas pertinentes, a que lo hicieran - de modo general - en un plazo razonable. Para resolver de ese modo, la Corte invocó las siguientes razones: (i) trascendencia de las cuestiones planteadas; (ii) las actuales condiciones económicas, que demandan una evaluación cuidadosa; (iii) la necesidad de adoptar "medidas de alcance general y armónicas", por la complejidad del gasto público y las necesidades a satisfacer. ${ }^{21} \mathrm{El}$ fallo incluyó la mención de una futura segunda sentencia, que calificó como diferida, después del informe que debía brindar la demandada (Agencia Estatal de Seguridad Social) sobre el aumento que tenía que otorgarse al jubilado.

El caso Badaro ha motivado diversas críticas. Por un lado, hay quienes vieron en él una suerte de evasión dilatoria de la Corte, al no resolver en concreto y puntualmente cuál era la cifra que debía cobrar. Desde otra perspectiva, sin embargo, se lo visualizó como una sentencia prudente y previsora, que procuraba moderar los efectos de un control de constitucionalidad inter partes, con soluciones que podían ser dispares según los distintos juzgados que resolvieran cada petición de cada uno de los miles de jubilados que se encontraban en situación similar que el actor Badaro. La Corte, en definitiva, buscó una solución global y la encomendó a quienes, según la Constitución, deben actualizar los haberes jubilatorios (en primer lugar, el legislador), quienes debían suministrar una respuesta que tuviese en cuenta los intereses y derechos de los jubilados con las posibilidades presupuestarias y las políticas generales del Estado.

De hecho, el 26 de noviembre de 2007 la Corte dictó la segunda sentencia - "diferida"-, y ordenó actualizar en concreto los haberes provisionales del actor Badaro, con el mecanismo de variaciones salariales elaborado por el Instituto Nacional de Estadística y Censos, al reputar insuficiente el aumento global de jubilaciones dispuesto por los poderes Ejecutivo y Legislativo.

También en 2007 (sentencia del 5 de septiembre) la Corte Suprema dictó una suerte de sentencia escalonada en Editorial Río Negro c. Provincia de Neuquén, al disponer (ante un amparo donde se discutía la distribución discrecional de publicidad oficial en los medios de difusión),

21 CSJN, Badaro, en El Derecho, Buenos Aires, 2006, 219-34. 
que el gobierno demandado debía presentar en el plazo de 30 días un esquema de asignación futura de dicha propaganda, alternativa que implica, al menos tácitamente, un segundo fallo donde se evalúe el acierto de dicho plan. ${ }^{22}$

\section{EFECTOS DE LAS SENTENCIAS CONSTITUCIONALES. POSICIÓN INICIAL}

Como en el caso estadounidense, la Constitución argentina de 1853-1860 nada dijo sobre la facultad judicial de control de constitucionalidad de normas, y menos sobre los efectos de las sentencias del caso. Solamente la reforma de 1994 contempló, para la acción de amparo, que "en el caso, el juez podrá declarar la inconstitucionalidad de la norma en que se funde el acto u omisión lesiva". El resto del sistema es producto del derecho consuetudinario constitucional, elaborado preferentemente por la Corte Suprema.

En el régimen argentino de control de constitucionalidad, lo resuelto por un tribunal común o por la Corte Suprema, tiene en principio, resultados solamente inter partes, esto es, para el caso concreto. Cada órgano tribunalicio es independiente de los demás en esa tarea de evaluación de constitucionalidad. Por ello, si una ley, $v$. gr., es declarada por alguien inconstitucional, ello "no tiene efecto derogatorio genérico", ${ }^{23}$ y solamente produce su inaplicación en el expediente donde así se decidió. A su turno, si la norma fue reputada constitucional, nada impide que otro tribunal, o el mismo, cambie de criterio y la descalifique como inconstitucional en otra sentencia.

La Corte Suprema ha alabado en su momento ese sistema de efectos singulares del control de constitucionalidad, de tipo concreto y no abstracto, porque lo contrario "importaría entorpecer la acción independiente de los otros departamentos del gobierno". ${ }^{24}$

Por lo expuesto, además:

22 CSJN, Jurisprudencia Argentina, 2007-IV fascículo 7, 14/11/07, p. 22, con nota de Néstor P. Sagüés: Problemas constitucionales por la distribución de la publicidad oficial en los medios de difusión.

23 CSJN, Jurisprudencia Argentina, 1991-I-273.

24 CSJN, Fallos, 139:65. 
a) una decisión sobre constitucionalidad o inconstitucionalidad de una norma, no se extiende al caso de otras normas análogas, ${ }^{25}$

b) un pronunciamiento de inconstitucionalidad, aún emanado de la Corte Suprema de Justicia de la Nación, no se proyecta a leyes o hechos futuros, ni implica una prohibición al legislador; ${ }^{26}$

c) la norma reputada por la Corte como inconstitucional, se continúa aplicando en los casos en que no haya sido judicialmente objetada; ${ }^{27}$

d) si un tribunal declara inconstitucional una parte de una norma, el resto de ella se efectiviza, incluso en el mismo proceso, cuando conserva unidad orgánica y puede seguir rigiendo con abstracción de lo alcanzado por el tramo que se declara inconstitucional;28

e) la declaración de inconstitucionalidad de un precepto implica que el juez debe decidir la litis prescindiendo de él, o sea, como si el mismo no existiera, ${ }^{29}$ por lo que tiene, lógicamente y como regla, efectos retroactivos. ${ }^{30}$

\section{MutACIONES, AVATARES Y CONTRADICCIONES ${ }^{31}$}

El panorama descrito registró —en parte - varios cambios jurisprudenciales que en última instancia llevan a producir un efecto vinculante, aunque condicionado, de los fallos de la Corte Suprema, generando significativas reglas de derecho procesal constitucional consuetudinario.

25 CSJN, Fallos, 253:253.

26 CSJN, Fallos, 247:325.

27 CSJN, La Ley, 72-724. Sin embargo, en 2001 la Corte Suprema ha aceptado la declaración de inconstitucionalidad de oficio por el juez, circunstancia que habilitaría la inaplicación de una regla reputada por el magistrado como opuesta a la Constitución, incluso sin pedido de parte. Véase CSJN, Fallos, 324:3219, caso Mill de Pereyra.

28 CSJN, Fallos, 214:177.

29 CSJN, Fallos, 202:184, 264:364.

30 Véase sin embargo infra, parágrafo 8.

31 El presente tramo se fundamenta en Sagüés, Néstor Pedro, Derecho procesal constitucional, cit., nota 20, pp. 276-282, aunque con modificaciones. Para un desarrollo más extenso, nos remitimos a Sagüés, Néstor Pedro, Derecho procesal constitucional. Recurso extraordinario, cit., nota 2, t. 1, pp. 184 y ss. Recomendamos en particular la lectura de Bianchi, Alberto B., Control de constitucionalidad, 2a. ed., Buenos Aires, Ábaco, 2002, t. 1, pp. 351 y ss., y de Legarre, Santiago y Rivera, Julio C. (h), "La obligatoriedad de los fallos de la Corte Suprema de Justicia de la Nación desde la perspectiva de los tribunales inferiores", Jurisprudencia Argentina, 2006-IV-1333. 
a) Doctrina del sometimiento simple. En los autos Magdalena Rivera c. Vicente García Aguilera (1870), un juez federal de primera instancia sostuvo que los juzgados federales "deben ajustar su procedimientos y resoluciones, a las decisiones de la Suprema Corte que en casos análogos dicte, haciendo jurisprudencia". La Corte confirmó esa sentencia "por sus fundamentos". ${ }^{32}$ De hecho, esta tesis importaba lisa y llanamente aceptar en Argentina el sistema anglosajón del stare decisis, o del valor del precedente. Y de cuando en cuando, la Corte reitera tal postura, al indicar, por ejemplo, que el sistema judicial se fundamenta en "la autoridad institucional de los fallos de esta Corte en su carácter de supremo intérprete de la Constitución Nacional y el consecuente deber de someterse a sus precedentes". 33

b) Doctrina del seguimiento condicionado, como deber moral. Años más tarde, en la causa Bernardo Pastorino, capitán de la barca Nuevo Principio c. Rouillón, Marini y Compañía, la Corte puntualizó que sus veredictos deciden solamente el caso concreto "y no obligan legalmente sino en él", pero añadió que "hay un deber moral para los jueces inferiores en conformar sus decisiones como la misma Corte lo tiene decidido en casos análogos a los fallos de aquel alto tribunal". Fundó su conclusión

principalmente en la presunción de verdad y justicia que a sus doctrinas da la sabiduría e integridad que caracteriza a los magistrados que la componen, y tiene por objeto evitar recursos inútiles, sin que esto quite a los jueces la facultad de apreciar con su criterio propio esas resoluciones y apartarse de ellas cuando a su juicio no sean conformes a los preceptos claros del derecho. ${ }^{34}$

Aquí se diseña, también con factura jurisprudencial, una versión más moderada del stare decisis: la doctrina del precedente rige como deber moral, y es factible apartarse de ese precedente si el juez inferior entiende claramente que no es jurídicamente correcto. Las bases de esta construcción son dos: el argumento aristocrático (los fallos de la Corte son mejores que los provenientes de otros tribunales) y el argumento de la economía procesal (evitar el desgaste que significaría apartarse del crite-

SJN, Fallos, 315:2392, considerando 7

34 CSJN, Fallos, 25:368. 
rio de la Corte, para suscitar así recursos que a la postre revocarían a la resolución rebelde).

c) Doctrina del seguimiento condicionado como deber institucional. En el caso Santín, Jacinto I., la Corte dio otra vuelta de tuerca para afirmar su superioridad. Después de sostener que "es incuestionable" que los jueces tienen libertad de juicio para pronunciar sus veredictos, alertó que esa facultad debía compatibilizase con el carácter definitivo de los fallos de la Corte Suprema, y "ello impone ya que no el puro y simple acatamiento de su jurisprudencia - susceptible siempre de ser controvertida como todo juicio humano en aquellas materias en que sólo caben certezas morales - el reconocimiento de la superior autoridad de que está institucionalmente investida". El Tribunal concluyó que apartarse de la jurisprudencia de la Corte, mencionándola pero sin controvertir sus fundamentos, significa desconocimiento deliberado de aquella autoridad, y apercibió a los jueces que así habían actuado. ${ }^{35}$

d) Situación actual. En Cerámica San Lorenzo, ${ }^{36}$ por ejemplo, se consolida la línea de Santín Jacinto: los jueces inferiores deben aplicar las reglas jurisprudenciales elaboradas por la Corte Suprema, y carecen de fundamento las sentencias que se apartan de ellas, "sin aportar nuevos argumentos que justifiquen modificar la posición sentada por el Tribunal, en su carácter de intérprete supremo de la Constitución Nacional y de las leyes dictadas en su consecuencia".

En P.L.B. se aclara que la doctrina predicha se funda en la "autoridad del tribunal", y lo es sin perjuicio del juez inferior de no seguir los lineamientos de la Corte, pero "fundándose en razones no examinadas o no resueltas" por ella. Dicho de otro modo, el juez podrá apartarse, pero no "sin justificación expresa" (Petrovic), y con "nuevos" fundamentos (Adriazola), distintos a los ya evaluados por la Corte. ${ }^{37} \mathrm{Y}$ ello ocurre tanto respecto de la doctrina sentada por la Corte en temas de derecho federal, como de derecho común (civil, penal, laboral, etcétera). ${ }^{38}$ Si la sentencia del juez inferior desconoce la doctrina judicial de la Corte sin dar motivos valederos para no seguirla, padece del vicio de arbitrariedad y podrá impugnarse a su turno por el recurso extraordinario federal (en tal

35 CSJN, Fallos, 212:59.

36 CSJN, La Ley, 1986-A-178.

37 CSJN, P.L.B., El Derecho, 136-453; Petrovic, Fallos, 325:1227; Adriazola, Fallos 324:3764.

38 CSJN, Encinas, Fallos 321:2294. 
sentido, ver el dictamen del procurador general en Ferreyra, sentencia del 21 de marzo de 2006). ${ }^{39}$ Es muy frecuente que la Corte, cuando enuncia su superioridad, no diferencia las áreas del derecho adonde prevalece.

Cabe advertir al lector que ocasionalmente, la Corte ha sido autocontradictoria, por ejemplo cuando ha dicho que "la facultad de interpretación de los jueces y tribunales inferiores, no tiene más limitación que la que resulta de su propia condición de magistrados, y en tal concepto pueden y deben poner en ejercicio toda sus aptitudes y medios de investigación legal, científica o de otro orden, para interpretar la ley, si la jurisprudencia violenta sus propias convicciones", ${ }^{40}$ tesis que obligaría a olvidar la eficacia vinculante de los fallos de la Corte. Algo similar ocurre cuando la propia Corte restringe su jurisprudencia obligatoria, al señalar que sus precedentes carecen de fuerza legalmente vinculante para los tribunales locales, en materia de derecho público local, o cuando explica que la tacha de arbitrariedad no se configura por la circunstancia de haberse apartado el tribunal a quo de la doctrina establecida por la Corte Suprema en otros casos y por vía distinta a la intentada. ${ }^{41}$

En definitiva, después de una larga y no siempre uniforme ni clara trayectoria, puede reputarse vigente hoy, y mas allá de su acierto o error, una regla de derecho consuetudinario constitucional elaborada por la propia Corte Suprema, que impone a los tribunales inferiores a ella el deber jurídico de seguir sus criterios, más allá de los casos donde fueron expuestos, y en todo los escenarios (derecho federal o común, o local). Puede hablarse entonces de una jurisprudencia vinculante u obligatoria de la Corte, pero condicionada: el tribunal inferior está habilitado para apartarse de ella, siempre que (i) lo haga de modo expreso; (ii) dé fundamentos que sean a) valederos, y b) diferentes a los ya examinados por la Corte.

De hecho, esta regla importa una interpretación mutativa por adición al texto constitucional, que suma a las competencias de la Corte Suprema enunciadas inicialmente en la Constitución, la que aquí se consigna, cuya

39 CSJN, Jurisprudencia Argentina, 2006-II-210.

40 CSJN, Ferrocarril del Sud, Fallos, 131:109, 263:255.

41 CSJN, Fallos, 304:1459. Véase también Fallos, 306:1452, y 307:1264; Sodero, Eduardo R., "Sobre la responsabilidad científica del juez", en Santiago, Alfonso (h) (dir.), La responsabilidad judicial y sus dimensiones, 2006, Buenos Aires, Hammurabi, t. II, p. 520, nota 240 . 
legitimidad, hoy día, se fundamenta en razones parecidas al stare decisis estadounidense: igualdad, previsibilidad y economía. Son estos valores muy prácticos que la sociedad contemporánea cotiza significativamente, y que consolidan al peculiar stare decisis argentino, que como su par estadounidense, aunque no de modo idéntico, recorta las facultades de juzgamiento de los jueces y el mismo control difuso de constitucionalidad, al imponerles límites acerca de cómo deben resolver. En efecto, el juez argentino que debe decidir un acuse de inconstitucionalidad a una ley, si el tema fue ya definido por la Corte Suprema, carece de la libertad de decisión que tiene si el asunto no fue evaluado por la Corte. En los puntos resueltos por ésta, de hecho se perfila un control cuasi concentrado, y menos difuso. ${ }^{42}$

Por último, cabe tener presente que el legislador alguna vez ha dispuesto que los jueces inferiores deben seguir la jurisprudencia de la Corte Suprema en asuntos análogos (así lo hizo el artículo 19 de la Ley 24.463 , en materia provisional, aunque tal precepto se encuentra hoy derogado por la Ley 26.025).

\section{LA CORTE SUPREMA Y EL SEGUIMIENTO DE SUS PROPIOS PRECEDENTES}

Corresponde ahora detenerse en el respeto, por la Corte Suprema, de sus propios antecedentes.

En Provincia de San Luis c. Cía. de electricidad de los Andes, ella señaló que

si bien es cierto que la autoridad de los precedentes judiciales no es siempre decisiva, también lo es que si las circunstancias del caso no revelan claramente el error o la inconveniencia de las decisiones anteriores, haciendo ineludible un cambio de criterio respecto de la cuestión jurídica decidida, corresponde aplicar la doctrina de los mencionados antecedentes. ${ }^{43}$

42 Véase, en tal sentido, Sagüés, María Sofía, "Las acciones afirmativas en los recientes pronunciamientos de la Suprema Corte de Justicia de Estados Unidos. Implicancia del dato sociológico en el análisis jurisprudencial”, Proceso y Constitución. Revista Iberoamericana de Derecho Procesal Constitucional, México, núm. 2, 2004, p. 225.

43 CSJN, Fallos, 183:409, 192:414, 212:327. 
En Sieburger c. INTA, agregará que si la sentencia impugnada se sustenta en los precedentes análogos decididos por la Corte, tiene que confirmarse el fallo, salvo que se aporten nuevos fundamentos que desvirtúen los que se adujeron en aquellas causas. ${ }^{44}$ El stare decisis "criollo" parece pues obligar también a la misma Corte, con dos excepciones: a) que el cambio fuera "ineludible" (versión más rígida), y b) que se suministraren nuevos argumentos para la mutación (versión más flexible).

Sin embargo, la Corte, cuando varía de criterio, no siempre explica debidamente el porqué del cambio. En Sejean, por ejemplo, ${ }^{45}$ dio un audaz paso en adelante al reputar inconstitucional una regla de la ley de matrimonio civil que impedía a los divorciados contraer nuevo matrimonio. La Corte hizo una larga serie de explicaciones a favor de su postura, y de una interpretación dinámica (y quizá mutativa) de la Constitución, aludió a otros cambios operados por el Tribunal (por ejemplo, en materia de indexación), pero no se detuvo detenidamente en precedentes que, como Firpo, ${ }^{46}$ avalaban la constitucionalidad de la prohibición que ahora se removía.

En honor del Tribunal cabe reconocer que en otras sentencias asumió expresamente la actitud de cambio, mencionó los precedentes que se abandonaban y la tesis que se reimplantaba o afirmaba como nueva. Así, por ejemplo, en Montalvo, ${ }^{47}$ donde vuelve a declarar constitucional el castigo penal por la mera tenencia de estupefacientes, dejando de lado la doctrina de Bazterica y Capalbo. ${ }^{48}$

En otros supuestos, cuando es abandonado un criterio adoptado en su momento por un voto mayoritario y contradicho por otro minoritario, la Corte explica algunas veces la mutación remitiéndose a los fundamentos del anterior voto minoritario (ahora mayoritario, en el nuevo pronunciamiento). Tal fue el caso Bustos, ${ }^{49}$ donde la Corte sustituye la doctrina precedente de Provincia de San Luis, ${ }^{50}$ aunque parte de los jueces de la corte no dudan de calificar como "funesto" otro fallo que también se

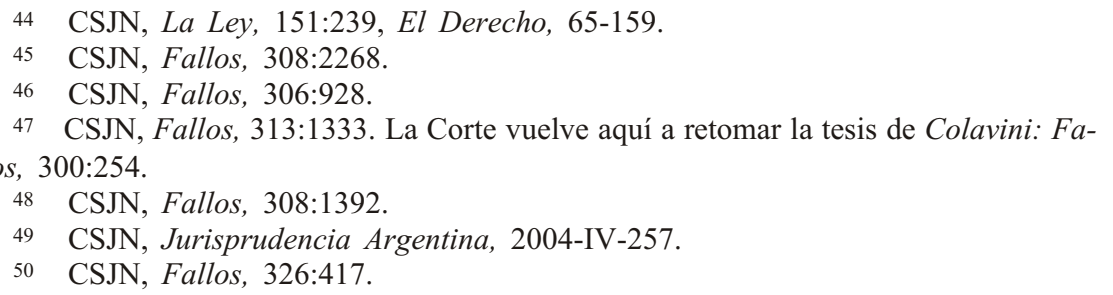


abandonaba. ${ }^{51}$ El muy importante tema en danza estribaba en la pesificación de depósitos bancarios originariamente pactados en dólares, sistema que en definitiva quedó (en esos autos, y al menos en parte) convalidado por la Corte.

En 2006, en el caso B., A. D. contra Provincia de Buenos Aires, la Corte ha hecho un rexamen de la situación. Como regla, advirtió, es bueno que ella siga sus anteriores precedentes, "a fin de preservar la seguridad jurídica que resulta de dar una guía para la conducta de los individuos", y cita al respecto el caso registrado en Fallos, 248:115. Pero alerta que tal regla no es absoluta ni rígida, y que no impide mutar de criterio, "pues los tribunales no son omniscientes", y deben aprovechar de la experiencia y del error, del ensayo y de la reflexión. Para producir el cambio, continúa el Tribunal, deben darse algunos de estos supuestos: a) "causas suficientemente graves" que provoquen ineludiblemente la transformación de su jurisprudencia; b) o que "medien razones de justicia", entre las que se encuentra el reconocimiento del carácter erróneo del precedente, la adecuada apreciación de las lecciones de la experiencia o los cambios históricos, cuando éstos aconsejan abandonar el criterio establecido. ${ }^{52}$ Como puede apreciarse, es todo un vademecum de pautas para justificar el abandono de sus precedentes, cuya autobservancia no resulta entonces sagrada ni mucho menos.

Pocos meses después de la sentencia mencionada, en Gramajo (fallo del 5 de septiembre de 2006), ${ }^{53}$ la Corte Suprema abandonó explícitamente (considerando 30) la doctrina anterior que ella tenía - caso Sosa-, 54 en materia de la constitucionalidad de la imposición de la sanción de reclusión a los multirreincidentes. La Corte fundó largamente el porqué de su nuevo criterio, opuesto a la constitucionalidad de la referida pena de reclusión por tiempo indeterminado, pero no atacó de modo expreso y puntual las bases del precedente que se removía, dictado escasos años atrás.

51 La sentencia - precedente al fin - calificada como "funesta" en Bustos por los jueces Belluscio y Maqueda es Smith (CSJN, Fallos, 325:28).

52 CSJN, B., A. D. contra Provincia de Buenos Aires, en Jurisprudencia Argentina 2006-II-92.

53 CSJN, Jurisprudencia Argentina, 2007-I-529.

54 CSJN, Fallos, 324:2153. 


\section{EVASIÓN Y SOMETIMIENTO DE LOS TRIBUNALES INFERIORES}

La actitud de los órganos tribunalicios inferiores a la Corte Suprema de Justicia de la Nación (sean nacionales o provinciales), frente a las directrices sentadas por ella, ha sido dispar. Naturalmente, no estamos hablando del respeto y obediencia a una sentencia de la Corte en el propio expediente donde se emitió, caso en que solamente corresponde su "leal acatamiento", como gusta decir aquélla, sino al seguimiento de la doctrina sentada por el Tribunal, en otros casos similares al que cabe decidir.

a) Algunas veces hay actitud de obediencia, en función - por ejemplo- de la "jerarquía y prestigio del alto tribunal". ${ }^{55}$

b) En otras ocasiones se pregona una suerte de sometimiento parcial: habrá de seguirse a la Corte Suprema en temas de derecho federal, pronunciados en virtud del recurso extraordinario federal, pero no en asuntos de derecho "común" (civil, comercial, penal, laboral), sobre los cuales muchas veces la Corte Suprema se expide en instancia originaria y exclusiva. Estos asuntos, en principio, son de competencia de las jurisdicciones ordinarias provinciales, a tenor del artículo 75 inciso 12 de la Constitución Nacional. ${ }^{56}$

c) De cuando en cuando se habla del sometimiento "moral" a las sentencias de la Corte Suprema, pero no "legal" (en los hechos, ello parece entenderse como un seguimiento más tenue y en definitiva no coercitivo). ${ }^{57}$

d) Ciertas sentencias exigen, para obedecer a la jurisprudencia de la Corte Suprema, que ella sea reiterada. ${ }^{58}$

e) En una postura igualmente exigente, algunos tribunales demandan que el fallo de la Corte Suprema con efectos expansivos, sea dictado por unanimidad. Si no tiene tal cualidad, disminuye su peso jurídico. ${ }^{59}$

55 Por ejemplo, Cámara del Trabajo de Rosario, sala II, Jurisprudencia Argentina, 13-1972-617.

56 Véase por ejemplo Cámara Civil de Rosario, en pleno, Juris 60-190; Suprema Corte de Justicia de la Provincia de Buenos Aires, El Derecho, 59-259, La Ley, 1975-A-736.

57 Cámara Nacional Federal en lo contencioso administrativo, Sala I, La Ley, 151-394.

58 Ibidem, 1975-B-565.

59 Cámara Nacional Civil en pleno, La Ley, 1986-E-240. 
f) Determinadas sentencias subrayan el carácter condicionado al sometimiento de las directrices judiciales de la Corte, y autorizan la discrepancia dando fundamentos y cuando las circunstancias revelen el error o la inconveniencia palmaria del criterio establecido. ${ }^{60}$

g) A su turno, una colección de fallos se inclina por el no acatamiento a las doctrinas sentadas por la Corte Suprema federal, salvo desde luego que el órgano tribunalicio del caso, voluntariamente, las comparta. ${ }^{61}$

En términos generales, la sumisión de los tribunales inferiores tiende a acentuarse en la actualidad, tal vez por la insistencia de la Corte Suprema nacional en el valor de las doctrinas judiciales que enuncia, tal vez por razones de conveniencia y de simplificación del trabajo en decidir, por parte de los jueces inferiores, a como ya lo ha hecho la Corte federal.

\section{EL FACTOR TIEMPO}

Apuntamos precedentemente (véase parágrafo IV, in fine), que la lógica del sistema difuso o desconcentrado, con efectos para el caso concreto, lleva a otorgar - como regla - efectos retroactivos a la declaración de inconstitucionalidad.

No obstante, la Corte Suprema ha delineado excepciones, producto igualmente de su propio activismo. Cuando lo resuelto tiene efectos expansivos, acercándose a resultados erga omnes, algunas veces modera el criterio anterior, de aplicación ex tunc, disponiendo que lo resuelto rija - de algún modo - para el futuro, ex nunc. Por ejemplo, en Itzcovich, al declarar inconstitucional el recurso ordinario de apelación ante la propia Corte dispuesto por el párrafo primero del artículo 19 de la Ley 24.463, siguiendo a otros antecedentes resolvió que "las causas en que haya sido notificada la sentencia de Cámara (de Apelaciones) con anterioridad al momento en que el presente pronunciamiento quede firme, continuarán

60 Cámara Nacional Federal en lo contencioso administrativo, sala II, La Ley, 1975-A-240.

61 Suprema Corte de Justicia de la Provincia de Buenos Aires, La Ley, 1976-A-435. Posteriormente, esta doctrina ha sufrido mutaciones en el seno de esta Suprema Corte. 
su tránsito con arreglo a la norma cuya inconstitucionalidad aquí se dispone". ${ }^{62}$

A su turno, en Rosza, la Corte Suprema difirió la aplicación de la declaración de inconstitucionalidad de una norma, a un año del fallo, por las consecuencias caóticas que podría provocar la inmediata aplicación de una declaración de inconstitucionalidad, dentro del sistema judicial argentino. Se trata de un fallo con efectos diferidos, donde el Tribunal realiza una drástica aplicación de la doctrina de la interpretación previsora de la Constitución, vale decir, medidora de las consecuencias y verificadora de los resultados de un pronunciamiento de inconstitucionalidad. ${ }^{63}$

\section{LOS EFECTOS DE LAS SENTENCIAS DE LOS TRIBUNALES PROVINCIALES}

Normalmente, en las provincias se repite el panorama de control judicial de constitucionalidad difuso, y para el caso concreto, inter partes.

Existen sin embargo varias excepciones.

a) Ocasionalmente, algunas Constituciones provinciales confieren efectos expansivos a las sentencias de sus cortes supremas locales en materia de interpretación de la Constitución y de las leyes y normas como decretos, ordenanzas, reglamentos, etcétera, declarándolas "de aplicación obligatoria para los tribunales inferiores" (así, artículo 143 de la Constitución de La Rioja, v. gr. En sentido similar, artículo 209 de la Constitución de San Juan).

b) En otras provincias, ese efecto expansivo se dispone por vía de ley, como ha ocurrido en Río Negro, en algunos aspectos. Ello genera dudas sobre la constitucionalidad de tal dispositivo legal, porque podría entenderse que lesiona la facultad de los jueces, aparentemente derivada de la Constitución, de fallar con independencia de criterio, como nota distintiva del régimen difuso o desconcentrado de control de constitucionalidad.

62 CSJN, Itzcovich, en Jurisprudencia Argentina, 2005-II-723, considerando 31. La sentencia menciona como antecedentes a Téllez, Fallos 308:552, y Barry, Fallos 319: 2151 .

63 CSJN, Jurisprudencia Argentina, 2007-III-414. Sobre la "interpretación previsora" de la Constitución, derivamos al lector a Sagüés, Néstor Pedro, La interpretación judicial de la Constitución, cit., nota 10, pp. 83 y ss. 
c) En otras, existe una tendencia jurisprudencial, de las propias cortes supremas locales, de asumir por sí solas tal facultad, sin norma constitucional o legal habilitante. Entendemos que tal situación es inconstitucional. No porque la Corte Suprema de Justicia de la Nación lo haya hecho para sus fallos, consumando una discutible exégesis mutativa de la Constitución, por su condición de intérprete final de ella, cabe concluir que las cortes supremas provinciales están habilitadas para, por su propia voluntad, realizar lo mismo en su ámbito doméstico.

d) Ciertas Constituciones provinciales habilitan a su corte suprema local a suspender la vigencia de una norma reputada inconstitucional por dicha corte, si lo ha hecho por unanimidad y por tercera vez (v. gr., artículo 159 de la Constitución de Tierra del Fuego). La de Río Negro, más terminante, dispone que cuando ese pronunciamiento de inconstitucionalidad sea adoptado por unanimidad y por tercera vez por su superior tribunal, en proceso contencioso, éste podrá, por pronunciamiento expreso adoptado por separado, declarar abrogada la norma. Si la regla en cuestión fuese una ley, el Superior Tribunal deberá dirigirse a la Legislatura "a fin de que proceda a eliminar su oposición con la norma superior. Se produce la derogación automática de no adoptarse aquella decisión en el término de seis meses de recibida la comunicación del Superior Tribunal quien ordenará la publicación del fallo" (artículo 208). La cursiva es nuestra.

e) En la ciudad autónoma de Buenos Aires, existe un mecanismo sui generis: en las acciones declarativas de inconstitucionalidad, que se diligencian de modo originario y exclusivo ante el Superior Tribunal de dicha jurisdicción (equivale a una corte suprema provincial), "la declaración de inconstitucionalidad hace perder vigencia a la norma salvo que se trate de una ley y la Legislatura la ratifique dentro de los tres meses de la sentencia declarativa por mayoría de los dos tercios de los miembros presentes", en cuyo caso se aplicará solamente al caso concreto (Constitución local, artículo 113 inciso 2). Según medie o no ratificación de la ley por la Legislatura, mediante aquel sistema de renvío, el fallo tendrá pues resultados inter partes, o erga omnes, en este último supuesto con derogación de la norma referida. La nueva Constitución de Santiago del Estero (artículo 193 inciso 1-b), adopta la misma solución.

f) Eventualmente, determinados textos constitucionales han previsto que cuando tribunal superior de justicia o corte suprema provincial de- 
clara la inconstitucionalidad de una norma, ello produce la caducidad de la parte afectada por tal declaración (así, artículo 9o. de la Constitución del Chaco, texto de 1994).

g) Otra ruta es la prevista, $v$. gr., por el artículo 11 de la Constitución de la Provincia de San Juan. Cuando una norma es declarada inconstitucional por su Corte de Justicia, tal decisión "debe ser comunicada formal y fehacientemente a los poderes públicos correspondientes, a los fines de sus modificaciones y adaptaciones al orden jurídico vigente", lo que importa identificar a estos fallos como una especie de sentencias exhortativas.

Como puede advertirse, existen múltiples modalidades de efectos del control de constitucionalidad en el ámbito provincial, conformándose así regímenes llamados "atípicos", explicables en un sistema político federal donde reina el principio de legitimidad de la variedad.

\section{Recapitulación. Conclusiones}

En el orden nacional, el control de constitucionalidad, heredado del sistema estadounidense, ha evolucionado primero al admitir, aparte de las sentencias clásicas, admisorias o desestimatorias del planteo de inconstitucionalidad, fallos atípicos del tipo de las sentencias interpretativas, manipulativas (aditivas, sustractivas, sustitutivas), exhortativas y escalonadas.

Acerca del efecto de las sentencias constitucionales, el esquema constitucional originario fue, dentro de los marcos de un régimen difuso o desconcentrado, con resultados inter partes. Sin embargo, y por su propia decisión, y más allá del texto constitucional, la Corte Suprema de Justicia de la Nación ha elaborado un derecho consuetudinario procesal constitucional donde sus veredictos tienen efectos expansivos, erga omnes, con cierto parentesco con el stare decisis estadounidense, en el sentido que la doctrina que ella fije debe ser obedecida por los demás tribunales inferiores del país, nacionales o provinciales. No obstante, ellos pueden excepcionalmente apartarse de aquellos lineamientos, siempre que lo hagan de modo expreso, con fundamentos valederos, y también distintos a los ya meritados por la Corte Suprema.

El éxito de la tesis del efecto vinculante, aunque no absoluto, de las pautas que fija la Corte Suprema, se explica básicamente por razones de 
igualdad de trato, y de seguridad o previsibilidad, por parte del mercado forense, y de la sociedad toda.

A su turno, la misma Corte se obliga a continuar con sus precedentes, aunque admite salvedades (razones de justicia, evolución del contexto fáctico, lecciones de la experiencia, doctrina anterior equivocada). Sin embargo, no siempre el Tribunal es claro cuando abandona una posición por otra, y no en todos los casos da motivos suficientes para explicar el cambio.

Por su parte, los tribunales inferiores han sido muchas veces reacios a obedecer las directrices de la Corte Suprema de Justicia de la Nación, habiendo elaborado varias excusas para evadirse. Actualmente, sin embargo, la dosis de seguimiento es bastante alta.

En función del tiempo, de ordinario, las sentencias sobre inconstitucionalidad cuentan con aplicación retroactiva, pero también existen salvedades, en particular cuando tienen fuertes efectos expansivos, caso en el que se justifica una prudente interpretación previsora de lo resuelto.

En definitiva, rige aquí un fluctuante y flexible derecho consuetudinario que registra cerca de un siglo y medio de mutaciones, no siempre coherentes ni consolidadas.

En la esfera del derecho constitucional provincial, hay múltiples modalidades en cuanto los efectos de las sentencias constitucionales. En varias provincias y en ciertos casos los veredictos de sus cortes supremas o tribunales superiores tienen efectos expansivos, ya derogatorios, ya suspensivos, de las reglas reputadas inconstitucionales. En algunos supuestos, el resultado inter partes o erga omnes depende de que el Poder Legislativo local ratifique o no a la ley declarada inconstitucional por la Corte Suprema provincial. 